\title{
Revealing the Role of Electronic Media in Shaping Multilingual Children
}

\author{
Andini S. Athalia ${ }^{1}$ Asrori Asrori ${ }^{1, *}$ \\ ${ }^{1}$ State University of Surabaya, Indonesia

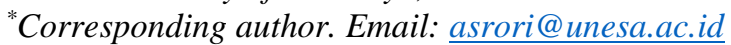

\begin{abstract}
Natural bilingual children are those whose languages are acquired through their parents and community. However, this paper aims to analyse how bilinguals are shaped early within their life as children through the help of electronic media. This method aims to reveal the role of electronic media in shaping bilingual children using Piaget's cognitive development theory. This study applied the qualitative method, and the data were taken from a series of interviews of three subjects who were all avid media consumers as a child. The results showed that parents exposed their children to these media because it can help their children pass the time or simply do not have the time to play with their children. Children later processed the media through their cognitive ability, which in turn affects their behaviour and language development. Children mostly imitate the shows they watched either from behaviour or language. Lastly, this study also found that children who have the most exposure to foreign media have a better chance of becoming bilingual.
\end{abstract}

Keywords: Bilingual, Multilingual, Electronic media, Bilingual children, Multilingual children.

\section{INTRODUCTION}

Children from the age of 3 to 10 years old are considered as explorers, watching almost all objects they encounter. Either from television or any other media like the internet. Especially cartoons or any other children television shows. Several studies have shown that children seem to have rich media experiences from their homes [1]. Many studies have researched the effects of cartoons and any other electronic media on children's cognitive ability. Previous research has stated that at the cognitive level, children also can understand stories and conversations [2]. These cartoons also can shape children as they grew up in various aspects such as behaviour and language acquisition.

Especially in language development, these cartoons often hail from different countries. Thus, they could be in different languages. There are undoubtedly many cartoons that children know and love for English language, such as from Disney, Nickelodeon, Cartoon Network, and many more. Of the three types of bilingualism, compound, coordinate, and sub-coordinate [3], these children are the ones we call compound bilingual. Compound bilinguals learn two or more languages as they process the world around them and simultaneously develop two linguistic codes [3]. The researcher has found that children who watch shows with different languages at the age of 5-10 years old, have better abilities in processing languages. They tend to become bilinguals as they grew up compared to children who only watch shows in their own mother language. These are also influenced by their family's background, economy, and environment.

In a previous study, it focused on discussing children's cognitive development in general that was influenced by Upin and Ipin [2]. The result of this study was that Upin and Ipin has a good effect on children's cognitive development. The children were able to sketch a kite and made them. The research also states that children were able to recognize colours from the show. Another research also focused on how bilingual children are shaped [4]. This study shows that bilingual children simply followed a different route than monolingual children, which is seen as approximations of their input systems.

Simply put, bilingual children have two grammatical systems. The last one is a study focused on how children acquire their second language [5]. The results showed that children acquire their second language faster than adults. 
There are four research questions: (1) what made their parents show these media to their children? (2) How does the child process these shows? (3) How do the media affect children's behaviour and/or language development? (4) What is the difference between children exposed to foreign electronic media and children exposed to only local media?

Based on the research questions above, the purpose of this research is to unravel how electronic media, especially cartoons can help children's cognitive ability in language acquisition, which has not been done in previous researches.

\subsection{Cognitive Ability}

Cognitive ability is the ability to think of the activities mentioned and then figure out the way to perform those activities. To understand cognitive ability followed by cognitive style, and finally, learning preferences. The ability to think of words or images is referred to as cognitive ability, or spatial low, and high cognitive style [6]. Every child develops at different stages. However, one's cognitive abilities can be significantly improved. In every individual, an internal mechanism exists in the mind, and this mechanism develops based on the individual's capacity for adaptation to their environment. During the test, there will be brain activity, which will give you cognitive processes known as determinatives [7].

\subsection{Language Acquisition}

The cognitive development hypothesis proposed by Jean Piaget states that children's intellect grows throughout their lives. Although obtaining information is a necessary part of child development, children also have to think about how the world works and develop their ideas about it [8]. The formation of a child's cognitive abilities results from intrinsic capabilities and contextual experiences, and children go through phases in their development. According to Piaget, the stages are: (1) Sensorimotor stage (birth to 18-24 months), (2) Pre-operational stage (2-7 years old), (3) Concrete operational stage (7-11 years old), and (4) Formal operational stage $(12+$ years old).

All civilizations have the same invariant or unchanging sequence of phases. Children go through similar phases in the same sequence during every age period, but not all at the same rate.

\subsection{Three Types of Bilingualism}

According to Francis Grosjean, bilinguals are those who speak more than one language. In their everyday lives, people may become bilingual either by acquiring two languages at the same time in childhood or by learning a second language sometime after acquiring their first language. Many bilingual people grow up speaking two languages. There are three types of bilinguals: (1) Compound bilinguals are those who work with two sets of concepts. They learn two languages as they process the world around them, (2) Coordinate bilinguals are those who work with two sets of concepts in entirely different contexts, and (3) Sub-coordinate bilinguals are those who learn another language by filtering it through their mother language [3].

\subsection{The Role of Electronic Media in Shaping Multilingual Children}

Electronic media is a medium in which we receive information. This information is delivered to us via electronic devices such as television. Children are basically a bowl that is being poured water. They will receive any information that is provided to them consciously and subconsciously. And they will try to mimic or find any other way of reflecting that information [2].

\section{METHODS}

This research uses a qualitative research method to collect the data. The data collected are analysed and reported descriptively. The questions provided are those that had been prepared for interviewing subjects as the research target. The data for this research are taken from interviewing three subjects. These three subjects are the most fitting of the criteria. As for the criteria, the subjects need to be avid consumers of electronic media during their childhood, approximately during 5 to 11 years old of age. As of now, the subjects' ages are ranged from 21 to 25 years old. These subjects also took CEFR tests with varying results before the interview.

There are a few additional questions in correlation with the subjects' answers. The three subjects will be referred to as subject $\mathrm{A}$, subject $\mathrm{B}$, and subject $\mathrm{C}$ in this research. The results are analyzed using comparisons among the three subjects and each subjects' answers are analyzed in relation to their answers.

\section{RESULTS AND DISCUSSION}

\subsection{Subject A}

Subject A is a 22 years old entrepeneur from Bandung. They stated that their English skill would fall under the category of under average proven by CEFR level of A1. The results of the interview are the following.

The informant A stated that they often watched children shows as a child. Chalkzone and Spongebob Squarepants were their favorite. They watched those shows from an Indonesian TV channel, Global TV. 
Furthermore, they also stated that they were never exposed to foreign media as a child. Subject A then continued to state that they have problems in learning English even until now. Other than that, they stated that they often imitate behaviors of a character from the cartoon Chalkzone. They also stopped watching children shows when they were around 7 to 9 years old. Lastly, subject A stated the factor that caused them only to watch Indonesian media is that their family cannot afford to have cable TV which caused them to only watch Indonesian media and that English was second language. They did not grew up in an English-speaking community.

\subsection{Subject $B$}

Subject B is a 21 years old college student from Palembang. They stated that they could participate in a conversation using full English and were later proven with their CEFR level of B2. The results of the interview are the following.

As mentioned in the data, subject B often watched cartoons and was particularly fond of Naruto, SpongeBob Squarepants and $\mathrm{Yu}-\mathrm{Gi}-\mathrm{Oh}$ ! from Cartoon Network, Global TV and Spacetoon. They often imitate things from these shows, especially Naruto. They stated that they often imitate how Naruto would run during elementary school. Another point is when subject B is asked about their parents' reaction on seeing them watch and imitate those cartoons; they responded that as a child, their parents were not around much, so they watched a lot of television to pass the time. Subject B then stated that they watched those shows in both English and Indonesian, but mostly Indonesian. They also stated that these shows helped her in English a lot since they used to imitate how the characters would talk and how they often pick up vocabularies from the show to which they continue to state that they had little problem in learning English. Subject B stated that they only had problems in grammar and spelling. Furthermore, they stated that although they used to have cable television, they still prefer to watch shows in Indonesian because they understand them better. Lastly, subject B mentioned that their English ability is useful because they have to speak to foreigners a lot and that they consider themselves a trilingual because they mastered three languages. Subject B did not grow up in an English-speaking community.

\subsection{Subject $C$}

The last subject is subject $\mathrm{C}$, a 25 years old chef from Jakarta. Prior to the interview, subject $\mathrm{C}$ took a CEFR test and their CEFR level was in the advanced category which is $\mathrm{C} 2$. The interview results are the following.
From the data above, subject $\mathrm{C}$ mentioned that they watched mainly kid shows and were particularly fond of Blues Clues and The Backyardigans which they watched from Nickelodeon, an international children television channel. Subject $\mathrm{C}$ also mentioned that they imitate many things from the shows and used to sing the theme song from The Backyardigans often. Furthermore, subject $\mathrm{C}$ mentioned that they mostly watched these programs in English, which helped them a lot in learning English because they also imitated their accents and picked up vocabularies from them. Subject $\mathrm{C}$ only has problems in spelling because of their ADHD. They also mentioned that their parents were very supportive of them watching and imitating these TV shows. Lastly, subject $\mathrm{C}$ mentioned that their ability in English is very useful since they worked in an Englishspeaking environment. Thus, they speak English on a daily basis. Subject $\mathrm{C}$ did not grow up in an Englishspeaking community, but their parents teach them a little bit of English.

From the data provided above, it was found that the subject has the least problem in learning English as their second language is subject $\mathrm{C}$. Compared to other subjects, subject $\mathrm{C}$ is the subject with the most exposure to foreign media as a child. This shows that exposure from foreign media affect cognitive development, particularly in their language acquisition ability. Cognitive ability is the ability to think with words or images [6]. From the four stages of development [8], these children were mostly exposed during the second and third stages, the pre-operational and concrete operational stages. The second stage in Piaget's theory of cognitive development is referred to as the preoperational stage. This period starts about two years of age and lasts until about seven years. This time, youngsters are performing cognitive activities, but they are still in the process of thinking symbolically. The child's thinking during this stage is pre operations. This means the child cannot use logic or transform, combine or separate ideas [8]. A child's growth consists of making connections with the environment through trial and error and making an effort to move onto the concrete level when they are capable of utilizing logical reasoning. Children may cognitively depict events and things toward the conclusion of this period and engage in symbolic play. This correlates with how the subjects said that they would imitate things from their favourite shows such as actions, accents and picking up new vocabularies. According to Piaget, the third stage in his theory of cognitive development is the concrete operational stage. This age spans around seven to eleven years, and throughout this time, a child's capacity for rational and organizational thinking develops. It is also considered a major turning point in children's cognitive development because the child is now mature enough to use logical thought or operations but can only apply logic to physical objects [8]. This correlates with how 
the subjects mostly stopped watching cartoons in their concrete operational stage. Subject B and C both stated that these cartoons helped them in learning English. These are because they still watched these shows during their concrete operational stage. Both subject B and C stopped watching kid shows at 10 years-old in which they started to use logical thoughts.

From the data above especially subject $\mathrm{A}$ and $\mathrm{B}$, it is also mentioned that both subject $\mathrm{B}$ and $\mathrm{C}$ are bilinguals. Bilinguals are those who speak more than one language in their everyday lives. There are three types of bilinguals: (1) compound bilinguals, (2) coordinate bilinguals, and (3) sub-coordinate bilinguals [3]. This theory relates with how both subject B and C fall under the compound bilingual category who work with two sets of concepts, learning two or more languages as they begin to process the world around them. Both subject $\mathrm{B}$ and $\mathrm{C}$ were exposed to foreign media as a child. As children still processing the world around them, subjects B and C picked up English as their second language and Indonesian or Sundanese as their first language. As stated in previous studies, children tend to mimic what they see and even take things from it. Bilingual children's language development does not have much difference with monolingual children. The only difference is that bilingual children will soon realize who the inputs are from, depending on who is talking, and where and in what situation.

Another thing is that both subject $\mathrm{B}$ and $\mathrm{C}$ said they were able to afford cable TV which provides them with foreign media. However, subject A, said they could not afford them which in turn, subject A was not able to get any foreign exposure. This also shows that economy also plays a part in shaping children as bilinguals. These results are also proven with the results of each subject's CEFR tests. In which subject A's level is A1, subject B, B2, and subject C's level is C2.

\section{CONCLUSION}

From the data and explanations provided above, in relation to the aim of this study which is analysing the role of electronic media to children's multilingual ability, we can conclude that two out of three subjects are compound bilinguals. Subject A, who did not get any exposure to foreign media as a child, has problems in learning English even until they are 22 years old. As for subject $\mathrm{B}$, who still got exposed to foreign medias even though not many as a child, only has difficulties in English grammar and spelling while learning English. In the age of 21 years old, subject B is considered a trilingual, because they speak Indonesian, Sundanese, and English daily. Lastly, subject $\mathrm{C}$ is the one with the most exposure to foreign media as a child. According to subject C's statements, they had no problem in learning English aside from spelling due to their ADHD. At age
25, subject $\mathrm{C}$ considers themselves as bilingual, mastering both English and Indonesian, and speaking both languages daily. These subjects also have one thing in common; they did not grow up in an Englishspeaking community. From Piaget's four stages of cognitive development, these subjects watched kid shows in their pre-operational stage and concrete operational stage.

\section{REFERENCES}

[1] A. D. Houwer, "Bilingual Language Acquisition," in The Handbook of Child Language, 2017.

[2] J. Paradis, "Second Language Acquisition in Childhood," in Blackwell Handbook of Language Development, 2008, pp. 387-405.

[3] R. Mayer and J. Massa, "Three Facets of Visual and Verbal Learners: Cognitive Ability, Cognitive Style, and Learning Preference," Journal of Educational Psychology, vol. 95, no. 4, pp. 833-846, 2003.

[4] A. Bandura, "Social Cognitive Theory: An Agentic Perspective," Asian Journal of Social Psychology, vol. 2, no. 1, pp. 1-26, 1999.

[5] J. Piaget, "Part I: Cognitive Development in Children: Piaget Development and Learning," Journal of Research in Science Teaching, vol. 2, no. 3, pp. 176-186, 1964.

[6] N. A. Chomsky, "Verbal Behavior by B.F. Skinner," Language, vol. 35, no. 1, pp. 26-58, 1959.

[7] Wahyuni, F. Wiandari, S. Pratiwi and C. Panjaitan, "Effects of Cartoon Films on Cognitive Development in Early Childhood," The Roles of Parents in Shaping Children's Characters (ICECED), pp. 190-195, 2018.

[8] R. D'Acierno, "Three Types of Bilingualism," 24th INTERNATIONAL IATEFL CONFERENCE, p. 65 , 1990. 